\title{
THE BRITISH
}

\section{JOURNAL OF DERMATOLOGY.}

\author{
MAY, 1898
}

\author{
A CASE OF MYCOSIS FUNGOIDES. \\ BY ARTHUR WHITFIELD, M.D. (LOND.), M.R.C.P., \\ Assistant Physician to the West London Hospital.
}

Althovgr the literature of Mycosis fungoides is now very considerable, we are still entirely ignorant of the cause producing it, and, as every case ought to be investigated with a view to finding the parasite which is now generally believed to be the cause of the disease, I have thought it worth while to publish this case with the results of the pathological investigations made upon it. Of course the results here described are only negative, but negative evidence in a case of this sort is of value, since if any of the hitherto described organisms is to rank as the causal agent of the disease, it must at all events obey the first of Koch's laws-namely, that it must be demonstrable in every case of the disease.

As will be seen in the description given below, the case belonged to that variety of the disease which shows a very marked desquamating stage, the so-called lichenoid or eczematous period, and showed very little tendency to the formation of actual tumours, and it seems to me of great importance for all investigators to define the variety of the disease at which they have been working, since the differences between the disease here described, and the variety which occurs with tumours from the first, are so marked that the two varieties may well be the results of different causes.

John T., aged 64, married, admitted August 14th, 1897. Complains. of a rash all over him, and some sore places. 
Family History.-Both parents dead, cause unknown; mother used to suffer with an eruption on her head. One sister died of cancer. Another sister is living, and suffers with a rash similar to this patient's, but he has now lost sight of her for years. Patient states that a cousin living in London also suffers with a similar rash. (Unfortunately all attempt to find out more about these relatives resulted in failure.)

Personal History.-Patient has always been a healthy man, and has suffered from no illnesses with the exception of the usual complaints of childhood, and an attack of acute rheumatism. He has never suffered from any kind of venereal disease. About four years ago he noticed that when he undressed he used to shake off a quantity of small scales; he did not notice where they came from, but thinks they must have come from the head, as otherwise he would have noticed the scaliness on his skin. Soon after this he noticed that his skin became scaly all over, and began to itch slightly. Nothing further was noticed until about a year ago, when he found a swelling on the inside of the right upper arm. This grew to the size of a chestnut, and then burst through the skin, and, after persisting as a sore place for some time, healed up. Soon after this he found another flat swelling appearing on his back, which did not grow to any size, but sloughed out almost immediately, leaving an open sore, which has persisted up to the present time. Within the last few months more swellings have formed and broken down into sores, but he cannot remember in what order, or exactly when they came.

Present Condition.-The patient seems extremely feeble, but does not seem to notice it himself, and says he feels quite well. There is no sign of disease in any of the internal organs. The skin is covered with a general and almost universal eruption, not, however, affecting the palms or soles, which are merely somewhat harsh and scaly. On the face it exaotly resembles an ordinary ohronic eczema-that is, there is a diffuse and dusky redness all over the face, with some infiltration and considerable soaling. On the scalp a similar condition exists, but there is also a tendency to the formation of nodules and scabs, though there is no true ulceration present. The remainder of the body and limbs are affected alike everywhere. At the first glance the eruption somewhat resembles psoriasis, as it is a red rash, throwing off thick and rather silvery scales, and arranged 
in the gyrate manner so common in this disease. On closer inspection it is found, however, that these circles and curves are entirely made up of small nodules of a darkish-red colour, moderately firm to the touch, and $3 \mathrm{~mm}$. in diameter. In many places these nodules have grouped themselves together to form patches of various sizes, and have become covered with a thick, greasy scale, which, when removed, leaves a red and excoriated base, with a tendency to superficial ulceration. The larger patches, which look like tumours until the covering is removed, are covered with a true scab, also of very greasy quality, and beneath this is found ulceration of varying depth. The floors of these ulcers are covered with an offensive, greyish film, but there is in none of them any tendency to the formation of an adherent slough. There are six large ulcers in all, situated as follows:-On the back four, of which one is situated on the right shoulder, slightly above and to the inside of the inferior angle of the scapula, and is almost circular, deeply excavated, and about $1 \frac{8}{4} \mathrm{in}$. in diameter; another, much smaller and more superficial, about the size of a florin, lies on the eleventh rib, about 1 in: from the median line; a third, the largest of all, lies about 3 ins. below this, and on the right side, 1 in. from the vertebral column. This ulcer is ovoid in shape, with its long axis corresponding to the line of the ribs, and measures 28 ins. by $1 \mathrm{in}$. It is very deep, the base' being nearly half an inch below the skin surface; the floor is covered with a greyish deposit, and the edge is very hard, smooth, pinkish and everted, giving to it a strong resemblance to a malignant ulcer. About $3 \frac{1}{2}$ ins. below this lies another smaller ulcer, with the same characters, only less market. The other ulcers are two large ones on the front of the right thigh, near the groin. They also have the same characters, except that one is obviously formed from two smaller ones, which have coalesced to give the appearance of a single reniform ulcer. Where the skin is not obviously altered to the sight, it is nevertheless in an abnormal condition-that is, on touching the part it is found to be very dry and harsh to the feel, the epidermis wrinkling easily and showing a tendency to become detached with very little force. There is no sign of the normal secretions to be found anywhere.

The mouth is quite unaffected. 
The temperature on admission was $100.2^{\circ} \mathrm{F}$., and showed hectic variations throughout his stay in the hospital.

For the first week of his stay he seemed to improve slightly from the more frequent and efficient dressing of his sores, but at the end of the second he suddenly took a turn for the worse, and fell into the typhoid state, in which he remained for three days, when his friends came and insisted on taking him out, so that he was only a fortnight under observation altogether.

During his stay, however, I managed to get some photographs of him, and also two very small pieces of the diseased skin. Both of these fragments were taken from the nodular part of the disease, and one which was removed with careful aseptic precautions was implanted, by my friend Mr. Cheatle, under the skin of a guinea-pig. The small wound thus made healed up at once, and there was no effect on the guinea-pig's health afterwards, the tissue being completely absorbed. The second piece was examined histologically, and for micro-organisms. The search for the latter proved fruitless, in spite of the use of several methods of staining. (Gram, Neelsen, Weigert.)

It is, perhaps, noteworthy that the portions of tissue were taken from that part of the skin which had no tendency to break down, and therefore were less likely to contain accidental organisms than pieces taken from the edges of ulcers or already softened tumours. At all events, I was entirely unsuccessful in finding the cocci described by Stellwagon and Hatch, by using their method or any of the others I employed. Neither did I find anything like the psorosperms described by Wernicke; and although the organisms figured in his paper certainly suggest foreign organisms, I am surprised to find how different are the appearances of the other parts of the disease from those of my sections or the descriptions of others.

Histology. - The material from which I obtained my sections, and from which the following description is taken, consisted of a small piece of skin taken from the front of the thigh, just above the knee, containing two small nodules each of about the size of a hemp-seed.

On examination with a low power the following arrangement is seen :-The epithelium is seen to be subjected to pressure, so that the interpapillary processes are elongated and thinned out, the direction 
of the axes of many of the prickle cells being changed so that the long axis is vertical to the plane of the general cutaneous surface. In places the supra-papillary layers are diminished also, leading to an appearance not unlike that of psoriasis, more especially as the horny layer has a strong tendency to strip away from the underlying parts. With a higher power it can be seen that the granular layer is absent for the most part, only here and there a faint indication of it remaining. The intercellular spaces are much larger than normal, and in some places the cells themselves are swollen and distended. Many of the cells of the horny layer still contain well-preserved nuclei, the whole making up a condition of parakeratosis. As well as these alterations, there is also a slight but definite infiltration of the prickle layer with connective tissue cells and leucocytes, and, here and there there are appearances corresponding to the connective tissue cell-nests described by Unna, though for the most part I was unable to convince myself that these were not obliquely-cut apices of infiltrated papillæ.

I did not find any of the vesicular cavities caused by dilatation of the intercellular spaces described by Unna, but it is probable that my sections were taken from too early a stage of the disease to show these changes.

In the corium itself there is present a diffuse infiltration, occupying the papillæ, the subpapillary region, and extending some depth downwards, but not reaching the subcutaneous areolar tissue. The infiltration has no definite limits, but shades off gradually into the healthy tissue on all sides, disappearing last in the papillm themselves and the region immediately below them. The papilla are greatly enlarged in both length and width, but more especially so in width, being swollen out at the ends so as to become somewhat clubbed in shape. Even with the low power one is struck by the large size and want of any kind of uniformity in the cells forming the infiltration, as also by the absence of any relation in arrangement with the blood-vessels. On examining the edge of the nodule with a high power, it is seen that the collection of cells begins in the papillm themselves; at least, while the subpapillary region is atill free from infiltration, there is already to be seen an excess of connective cells in the papillæ. These cells at the edge of the nodule are for the most part moderate-sized, and oval or spindle-shaped; but, on passing 
more towards the centre, the infiltration is seen to be composed of distended cells of every possible shape, and of very variable size.

True giant cells are not to be found, nor have I been able to distinguish Unna's chorio-plaques " containing ten to twenty nuclei." Again, there was not present in my sections stained with the polychrome blue and glycerine-ether method that mass of granular, multiform particles supposed to be derived from the breaking up of the plasma cells. On the other hand I found plasma cells present only in great searcity, which is in agreement with Unna's observations. The vessels are generally dilated, but their walls are healthy, and, although surrounded by infiltration in the centre of the nodule, they do not seem to be the starting-point of the granuloma. Mast cells are present in moderate numbers. Even with the book beside me, I have been unable to follow the march of events and the almost too satisfactory explanation given by Unna, though in many points the appearances seen in my sections seem to correspond closely with his description.

That the patient was not longer under observation is a matter of deep regret to me, as I was only able to obtain such very small amounts for pathological investigation, and it was highly unwise to remove him in the state in which he was when he left the hospital. After leaving the hospital I lost sight of him completely, although I wrote to the doctor in whose charge he was before I saw him, and so I conclude that he did not reach home alive.

In conclusion, I have to thank Drs. Burney Yeo and Dalton for kindly allowing me to study the case while in hospital.

\section{URTICARIA WITH RECURRENT HÆMATEMESIS.}

BY T. HIULIER CHITTENDEN, M.D., M.R.C.P.

THE subject of this rare and interesting disease is a female about 83, unmarried, who consulted me in June last. She gave no history of any previous ill-health, except amenorrhœa, with a certain degree of anæmia, some eight months ago. The catamenia for the most part have been regular, although very profuse. 